$$
\text { تحليل حروف العطف ومعانيها في سورة النساء }
$$

\title{
Rahma Yani,
}

\section{Rahmayanii584@gmail.com}

شعبة تعليم اللغة العربيةكلية التربية وعلوم التعليمجامعة الإسلامية الحكومية بادانج سيدمبوان

$$
\text { تجريد }
$$

كانت اللغة العربية تتكون من الحروف والصرف والتركيبي والإستدلالي. والصريف

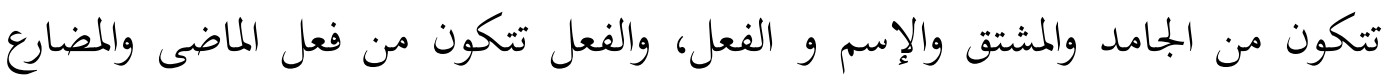
والأمر، ومن الحروف له حرف التوابع، وفي سورة النساء توجد عدة حروف ولإن العطف. وأما أهداف البحث هذا الموضوع هي معرفة حروف العطف في سورة النساء، لمعرفة معانيها.

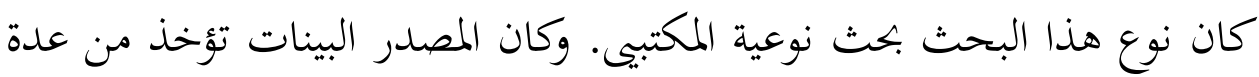
الكتب المتعلقة بالموضوع وكانت طريقة جمع معلومات هي: الجمع الكتب التي المتعلقة هما، تحليل معلومات، و كانت نتيجة البحث يعرض بالوصفية.

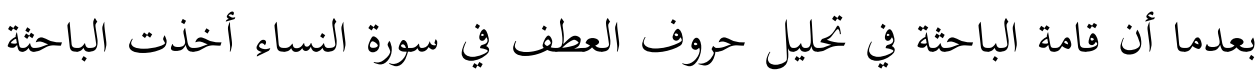
الإستنباط، فهي عدد حروف العطف الموجود في سورة النساء الأية ا-... حروف العطف فوجدت حروف العطف واو في Vq الاية بحروف العطف Y + T، وفاء

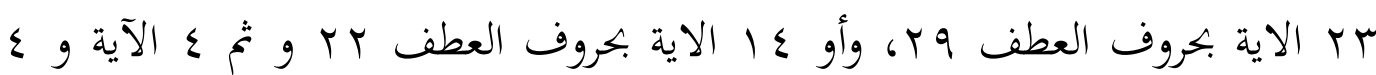
حروف العطف. واو بمعنى لمطلق الجمع، والفاء بمعنى للترتيب، وتم بمعنى للترتيب والتراخى، و أو بمعنى للتخيير. وجملة حروف العطف في سورة النساء الأية ا-...

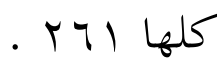
الكلمة المفتوحة: حروف العطف، تحليل معاني حروف العطف في سورة النساء 


\begin{abstract}
Abstrak
Bahasa Arab terdiri dari beberapa huruf, bentuk, susunan dan dalil-dalil. Sorof terdiri dari jamid, musytak, isim dam fiil, dan fiil terdiri dari fiil madi, mudhorik dan amar. Dan dari pembagian huruf-huruf ada yang dinamkan huruf yang mengikut \{harfu tawabi'\} yaitu naat, athof, taukid dan badal. Di dalam surah an=Nisa' terdapat beberapa huruf athof. Adapun tujuan peneliti membahas masalah ini ialah untuk mengetahui hut=ruf athof yang terdapat di dalam surah an-Nisa' ayat 1-100 dan mengetahui makna-makna nya.

Adapun jenis penelitian ini adalah penelitian pustaka. Sumber datanya diambil dari buku-buku yang berkaitan dengan judul dan metode mengumpulkan datanya ialah dengan mengumpulkan buku-buku yang berkaian dengan pembahasan kemudian menganalisanya. Adapun jenis penelitian ini ialah penelitian deskriptif.

Adapun sesudah peneliti membahas tentang judul analisis huruf athof pada surah an-Nisa' peneliti mengambil kesimpulan jumlah huruf athof yang terdapat dalam surah an-Nisa' ayat 1-100 dengan huruf athof wa terdapat di 79 ayat dengan huruf athof 206, fa terdapat di 23 ayat dengan huruf athof 29. Au terdapat di 14 ayat dengan huruf athof 22, dan Tsumma terdapat di 4 ayat dengan huruf athof 4 . Adapun makna nya ialah wa bimakna لمطلق الجمع, fa bimakna للترتيب والتعقيب, Tsumma bimakna للترتيب والتراخى dan Au bimakna للتخيير. Adapun jumlah huruf athof di surah anNisa' ayat 1-100 adalah 261 .
\end{abstract}

Kata Kunci: Huruf Athaf, Analisis Makna Huruf Athaf Dalam Surat Annisa' 


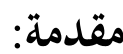

اللغة هى نعمة من نعام الله عز وجل الذي جعل الله لغة الإتصال بين الناس في العالم.واللغة كثيرة وهي مختلفة من حيث اللفظ متحدة من أي أن المعنى الواحد الذي يخالج ضمائر الناس واحد، ولكن كل قوم يعبرون عنه بلفظ غير لفظ الآخرين. فلذلك اللغة هي القدرة التي يمتلكه الناس على التفاعل مع الآخرين حتى يفهموا أهداف وغايات بعضهم البعض. بإستخدام اللغة يستطيع شخص أن يفهم قصد من

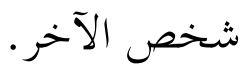

فا العلوم العربية هي العلوم التي يتوصل بها إلى عصمة اللسان والقلم عن الخطأ. وهي ثلاثة عشر علما وهي الصرف والإعراب (يجمعهما اسم النحو) والرسم و المعاني و البيان والبديع والعروض والقوافي وقرض الشعر والإنشاء والخطاء وتاريخ الادب ومتن اللغة' ـ إن اللغة العربية لغة القرأن و لغة أهل الجنة. هناك ثلاثة عناصر اللغة بيجب أن تعرف ويهتم في تعلم اللغة، وهي الأصوات والمفردات والتراكيب. فإن الأساس الأول لتعليم اللغة العربية هو علم النحو وعلم الصرف. علم النحو هو أحد فروع علوم اللغة العربية الذي يبحث عن كيفية تركيب الجمل التي تناسب مصطفى الغلاييني، جامع الدروس العربية، ج. 1، (بيروت- لبان: دار الفكر، V. . †)، ص.V 
بقواعد اللغة العربية، سواء المتعلقة بمكان الكلمات في الجملة أو حالة الكلمات (حركة النهائية والصيغة) في الجملة. كما قال الهاشيمي: النحو هو قواعد يعرف بها أحوال أواخر الكلمات العربية التي حصلت بتركيب بعضها مع بعض من إعراب و بناء وما يتبعهما.

علم أن علم النحو هو علم مهم جدا أن يتعلمه، وأماالطلاب والطالبات في دراسة العربية المشكلات متعلقات بعلم النحو، فهي مشكلات في شكل أي بشكل الأخر الكلمات وفي نظام الجمل. وحينما لا يتعلم فوجد في الأخطاء لأن اللغة العربية بدون النحو لن يكن فهما سواء كان إعرابها أم تركيبها، علم النحو هو العلم الذي يبحث في أصل تكوين الجمل وقواعد الإعراب في الجمل والكلمات والأحرف.

فهو العلم الذي يمدد أسلوب تكوين الجملة، ومواضع الكلمات في الجملة، ووظيفة كل منها كما يحدد الخصائص التي تكتسبها الكلمات من موقعها في الجملةمن حيث المعنى، والحركة، ومكاها. ويحدد كذالك الخصائص النحوية للجمل كالإبتداء، والفاعلية، و المفعولية، ويحدد أيضا الأحكام النحوية كحكم التقديم، و التأخير والإعراب

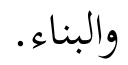
البحث الاول من علم النحو هو يعرف الكلمات وهو عند النحاة على ثلاثة أقسام وهي الإسم والفعل والحرف. والحرف يعرف بالعربية العامة لم تكن فيه دليل الاسم 
ولا دليل الفعل أي كل شيئ الذي لم بحد علامة الإسم ولا علامة الفعل. وتصنف الحرف قدم الشيخ المصطفى الغلايين في كتاب جامع الدروس العربية هو الحرف هو مادل على معنى في غيره، مثل هل وفي ولم وعلى وإن ومن. وليس له علامة يتميَّ . ما كما للاسم والفعل. ويبحث عن الأنواع الحروف. وهو ثلاثة أقسام حرف مختص بالفعل بالاسم كحروف الجر، والأحرف التي تنصب الإسم وترفع الخبر. وحرف مشترك بين الأسماء والأفعال كحروف العطف، وحرف الإستفهام.

هذا الباحث ستبحث عن تحليل حروف العطف ومعانيها في سورة النساء وعلاقتها في تعليم العربية. أما حروف العطف هو تابع يتوسط بينه وبين متبوعه حرف من أحرف العطف. وحروف العطف عشرة وهي الواو والفاء وثم وأو وأم و إما وبل ولا ولكن حتى. وهم توجه ومعانيها في سورة النساء.

سورة النساء هي سورة ع. سورة النساء هي سورة مدنية. قال العوفي عن ابن عباس في تفسير للحافظ بن كثير، نزلت سورة النساء بالمدينة. آياتما مائة وسبعون وست، نزلت بعد الممتحنة. وهي مدنية كلها فقد روى البخاري عن عائشة اها قالت:" ما نزلت سورة النساء إلا وأنا عند رسول الله صلى الله عليه وسلم" وقد بنى النبي بعائشة في المدينة في شوال من السنة الأولى مع الهجرة. rاحمد مصطفى المراغي، تغسير المراغي (حقوق الطبع محفوظة، عدم السنة), ص Vr 
وتقوم مدة البحث من شهر ينايير حتى يوني · · · r. أما نوع هذا البحث فهو

بحث المكتبة. همدف أبحاث المكتبة إلى جمع البيانات والمعلومات بمساعدة مجموعة متنوعة من المواد الموجودة في المكتبة مثل الكتاب والمجلات والسجلات والتاريخ وغيرها.

فلذلك بحث المكتبة هو عبارة عن بحث يجمع بيانات من الكتب أو المجلات أو

المستندات الموجودة في المكتبة. بحث المكتبة هو بحث يركز على المكاتبات ولا يحتاج الى الميدان. وفي حقيقتها، بحث المكتبة يمكن استخدام البيانات التي تم الحصول عليها من خلال كأساس وأداة رئيسية لإجراء البحوث الميدانية.

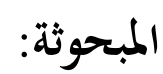

الحرف هو كلمة دلت على معنى في غيرها أو مالا يصله معه دليل الإسم ولا دليل

الفعل. فيعرف بأن لا يقبل شيئا من علامات الإسم ولا شيئا من علامات الفعل. كما قال العلامة الحرير في ملحة الإعراب : والحرف ما ليست له علامة * فقس على قولى تكن علامة. ّنقسم الحرف إلى قسمين و هي حرف المبني وهي منها تتكون الكلمات و حرف المعاني وهي كلمات لا يتم مدلولها الإضافتها إلى الإسم أو الفعل.

"العلامة السيد أحمد زيني دحلان، شرح مختصر جلدا على متن الآجرومية، (الحرمين، ا. . ب)ص. 
العطف في اللغة هو الرجوع إلى الشيئ بعد الإنصراف عنه. وفي إصطلاحا

نوعان، عطف البيان بغير حرف وعطف النسق وهو ماكان بحرف.؛ العطف هو تابع يتوسط بينه وبين متبوعه حرف من أحرف العطف. ْحرف العطف تشترك المعطوف مع المعطوف عليه لفظا وحكما.7

فعطف هو التابع الذي يتوسط بينه وبين متبوعه حرف من أحرف العطف. أحرف العطف هو الواو وافاء وثم وأو وأم وإما وبل ولا ولكن وحتى. فإن عطفت بها على مرفوع رفعت أو على منصوب نصبت او على مخفوض خفضت او على مجزوم جزمت.

ولعلهم سموه نسقا لانه ينسق الكلام بعضه على بعض، بكيث يأخذ المعطوف

نسق المعطوف عليه في أحكام دعينة، ونوجز لك الحديث عن حروف العطف.^

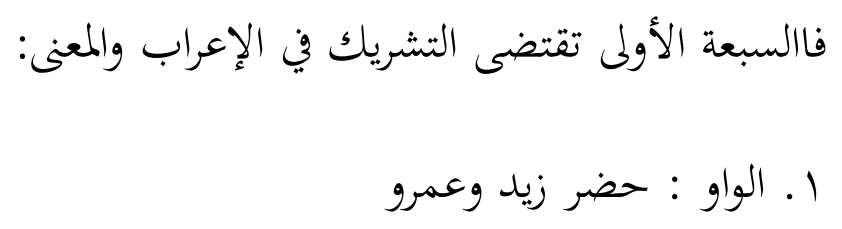

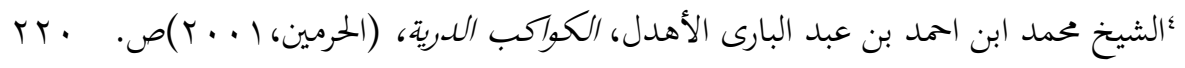

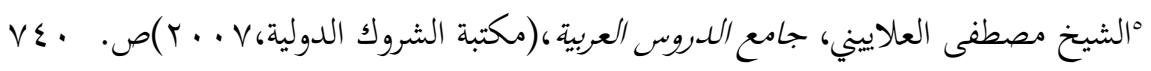

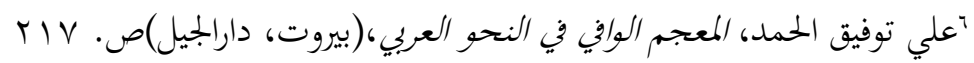

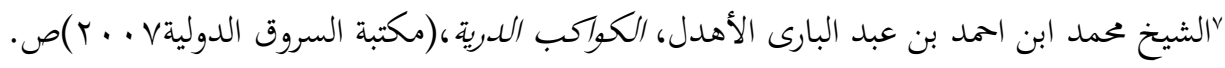

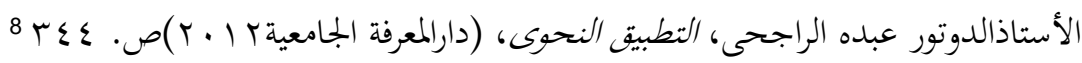




$$
\begin{aligned}
& \text { r ـ الفاء : استقبل القبلةُ فكبر } \\
& \text { r. أو : اختر الشعبة الأدبية أو العلمية } \\
& \text { ع. أم : قرأت الجلة أم الجريدة } \\
& \text { ه. حتى : أكلت السمكة حتى رأسها } \\
& \text { 7. لكن : هو جميل لكن متكبر } \\
& \text { V. إما : تعلم في المسجد أو في الغرفة } \\
& \text { والثلاثة الباقية تقتضي التشريك الإعراب:9 } \\
& \text { ا ـ ثم : سافر عمرو ثم رسالان } \\
& \text { r. بل : لم ينجح زيد بل علي } \\
& \text { r. لا : ينجح المجتهد لا المهمل }
\end{aligned}
$$

فإن عطفت بها على مرفوع رفعت او على منصوب نصبت او على مخفوض

خفضت او على مجزوم جزمت نهو: قام زيد وعمرو، رايت زيدا وعمرا، ومررت بزيد

$$
\text { وعمر، زيد لمج يقم ولم يقعد. }
$$

$$
\begin{aligned}
& \text { 9 } \\
& \text { 'الشيخ امام الصنهاجى، متن الأجرومية، (علم جاياميدان)ص. }
\end{aligned}
$$


1. الواو: تفيد مطلق المشاركة اى أن المعطوف يشارك المعطوف عليه في الحكم دون النظر إلى ترتيب زمنى أو غيره، مثل: حضر زيد و عمرو. فالعطف هنا يفيد مطلق اشتراك زيد وعمرو في الحضور، دون أن يدل ذلك على أن زيداً حضر قبل عمرو، أو معه، أو قبله بفترة وجيزة، أو طويلة، أو حضر بعده. r. الفاء: تفيد الترتيب والتعقيب أى أن الحلكم يكون للمعطوف عليه أولا دون أن تكون هناك فترة طويلة للمعطوف، نخو: حضر زيد فعمرو. فالفاء هنا أفادت حضور زيد أولا ثم حضور عمرو (في عقبه) أى بعده بفترة وجيزة. للترتيب بأن يكون المعطوف بها متأخرا عن المعطوف عليه. والتعقيب بأن يكون المعطوف واقعا عقب المعطوف عليه متصلا به بلا تراخ ولا مهملة بينهما. r. ثم : تفيد الترتيب والمهلة أو التراخى أى أن الحكم يكون للمعطوف عليه أولا ثم يكون للمعطوف مع وجود فترة غير وجيزة، مثل: حضر زيد ثم عمرو. أفادت ثم هنا حضور زيد أولا، وحضور عمرو بعده بفترة أى مع شئ من التراخى. ع. أو : تفيد الإباحة والتخيير، وقد تفيد معانى أخرى نفهمها من القرائن. والإباحة معناه اختيار واحد من المعطوف أو المعطوف عليه أو الجمع بينهما، مثل: إذا أردت أن 
تحسن لغتك فأقرأ شعرا أو نثرا. أى اختر واحد منهما او اخترهما معا. أما التخيير فينبغي

$$
\text { اختيارا واحد فقط، مثل: اختر الشعبة الأدبية أو العلمية }
$$

$$
\text { ه. أم : وهي حرف عطف يفيد التسوية بين الشيئين، أو تعيين واحد منهما: }
$$

أ. فالتى تفيد التسوية هى التى ترد مع هزة التسوية وهي همزة لا تفيد الاستفهام بل تدخل على جملتين خبريتين معطوفتين بأم ولا بد أن يصح سبك مصدر من كل منهما، مثل: لن أهتم به سواء أنجح أم رسب. فالممزة هنا تسمى همزة التسوية، والجملة بعدها خبرية، وأم حرف عطف، ويصح سبك مصدر من الجملتين، إذ المعنى: لن أهتم به فنحاحه ورسوبه عندى سيان.

ب. والتى تفيد التعيين هى التى تأتى مع همزة الاستفهام، مثل: أحضر زيد أم

$$
\text { عمرو }
$$

7 ـ إما : تكون حرف العطف للتفصيل بشرط: يبجب أن يسبقه إما آخر. و إما

$$
\text { الأول ليس من حرف العطف. ويختلفان في إما الثان }
$$

$$
\begin{aligned}
& \text { أ.حرف إما الثانى ليس حرف العطف لأن سبق من قبل حرف الواو. } \\
& \text { نحو: غاب إما خالد و إما حمودد. } \\
& \text { ب.حرف إما الثان هو حرف العطف بمعنى أو. }
\end{aligned}
$$


V. بل : تكون حرف عطف حين يعطف مفردا على مفرد، نحو: هي جميلة متواضعة، هو غني بل سخي. وتفيد شيئين: أ. الإضراب : إذا كان ما قبلها كلاما موجبا، مثل: الإسكندرية عاصمة مصر بل القاهرة. بل هنا حرف عطف يفيد الإضراب الذي معناه إلقاء الحلكم السابق ونقله إلى

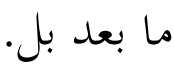
ب. الإقرار ثم المخالفة، وذلك إذا كان ما قبلها منفيا، مثل: لم ينجح زيد بل عمرو. بل حرف عطف، يفيد الإقرار بالحكم السابق أى بعدم نجاح زيد، سم مخالفة هذا الحكم

$$
\begin{aligned}
& \text { لما بعدها أى نجاح عمرو. } \\
& \text { م. لا : هي تفيد نفى الحكم عن المعطوف، ولا تكون حرف عطف إلا بشروط: } \\
& \text { أ. أن يكون المعطوف عليه مفردا } \\
& \text { ب. أن يكون الكالام قبلها غير منفي } \\
& \text { ج. ألا تقترن بحرف عطف، مثل: ينجح المجتهد لا المهمل? } \\
& \text { 9. لكن : وهي تفيد الاستدراك، نهو: هي شاطرة لكن متكبرة } \\
& \text { لكنها لا تكون حرف عطف إلى بشروط: } \\
& \text { أ. أن يكون المعطوف بها مفردا }
\end{aligned}
$$


ج. أن تكون مسبوقة بنفى أو فهى، مثل: لم أر الحادثة لكن سمعت بها

• ا ـ حتى: حرف من حروف العطف، هو العطف بها قليل، و شرط العطف بها أن يكون المعطوف إسما ظاهر، و أن يكون جزءا من المعطوف عليه او كالجزء منه، و أن يكون أشرف من المعطوف عليه أو أحسن منه، و أن يكون مفردا لا جملة، نو: يموت الناس حتى الأنبياء. و هذه حرف العطف معناها على أن المعطوف بلغ الغاية الزيادة او النقص بالنسبة للمعطوف عليه، كمثل: مات الناس حتى الأنبياء، وشرح عن الإعراب هو الأنبياء (المعطوف) والناس (المعطوف عليه) الذي معنى الغاية الزيادة او النقص. ولا تكون عاطفة الا باجتماع شروط اربعة:

يكون المعطوف بها إسما فلا يصح ان يكون فعلا ولا حرفا ولا جملة. نحو:

$$
\text { استخدمت وسائل الانتقال حتى الطيرة. }
$$

ب) أن يكون المعطوف بها إسما ظاهرا لا ضميرا ولا صريها لا مؤولا، فلا يجوز

$$
\text { اعتبارها حرف عطف، نحو: انصرف المدعون حتى انا. }
$$

ج) أن يكون المعطوف بعضا حقيقيا من المعطوف عليه. نحو: بالرياضة تقوى الا

$$
\text { عضاء حتى الرجل }
$$


بعد أن تبحث الباحثة هذه الرسالة تحت العنوان " تحليل حروف العطف ومعانيها في سورة النساء الأية ا - . . 1 وعلاقتها في تعليم اللغة العربية"، أخذت الباحثة الإستنباط، فهي أما عدد حروف العطف الموجود في سورة النساء الأية ا-.. . 1هي حروف العطف هم: واو بمعنى لمطلق الجمع توجد ج ، ب، والفاء بمعنى للترتيب والتعقيب توجد و ب، وثم بمعنى للترتيب والتراخى توجد ع، و أو بمعنى للتخيير توجد بr . وجملة حروف العطف في سورة النساء الأية 1-. . . كلها البץ . وأهمية حروف العطف في اللغة العربية علينا أن نرفع القبعة للغة العربية العظيمة، اللغة التى بها نقرأ القرآن والأحاديث، لغة بها الكثير من الكنوز، يمكنكم كتابة المزيد من الجمل التي فيها حروف العطف في التعليقات وشاركوا الموضوع أو ضيفوا له ما تحبون حتى يستطيع باقى قرائنا الأفاضل الاستفادة به. 


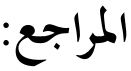

احمد مصطفى المراغي، تفسير المراغي (حقوق الطبع محفوظة، عدم السنة)

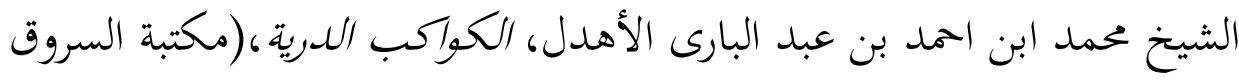

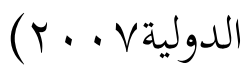

الشيخ محمد ابن احمد بن عبدالبارى الأهدل، الكواكب الدرية، (الحرمين، ا . . †)

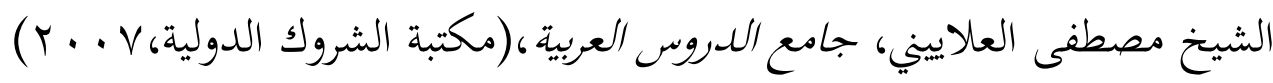
العلامة السيد أحمد زيني دحلان، شرح مختصر جدا على متن الآجرومية، (الحرمين، $(r \cdot \ldots)$

علي توفيق الحمد، المعجم الوافي في النحو العربي،(بيروت، دارالجيل)

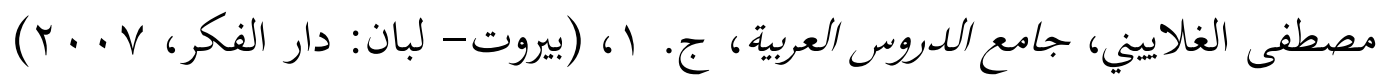

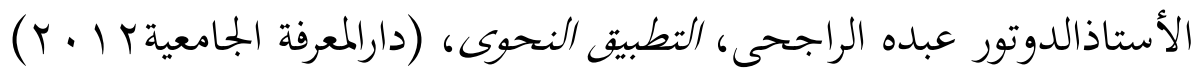

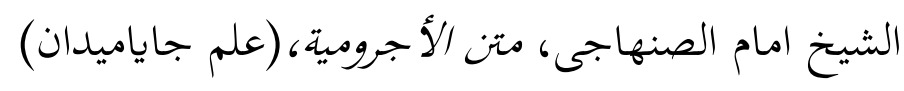

الأستاذالدوتور عبده الراجحى، التطبيق النحوى، (دارالمعرفة الجامعية ب ( ب ) 